\title{
Labordiagnostik bei Erkrankungen des unteren Respirationstrakts bei Reptilien
}

\author{
Rachel E. Marschang, Janosch Dietz, Kim O. Heckers
}

Pneumonien kommen relativ häufig bei Reptilien in Gefangenschaft vor. Dieser Umstand ist zum Teil durch die Anatomie ihres respiratorischen Systems bedingt (kein Zwerchfell, relativ einfache Lungenstruktur, z. T. Luftsäcke). Häufig werden Entzündungen des unteren Respirationstrakts durch Haltungsfehler begünstigt, wie zu geringe Temperaturen, Zugluft und mangelnde Hygiene. Oftmals werden diese Entzündungen chronisch und die primäre Ursache kann schwer festzustellen sein.

\section{Klinische Symptomatik}

Betroffene Tiere können relativ lange ohne auffallende klinische Symptomatik bleiben, sodass die Erkrankung meist schon fortgeschritten ist, wenn klinische Anzeichen einer Pneumonie auftreten. Eine Dyspnoe kann sich durch ein Hochstrecken des Kopfes beim Atmen (v.a. bei Schlangen) äußern, bei Schildkröten sind evtl. atemsynchrone Bewegungen der Gliedmaßen sichtbar. Schleim oder Flüssigkeit (auch Blut) in der Maulhöhle können Anzeichen für eine Entzündung des

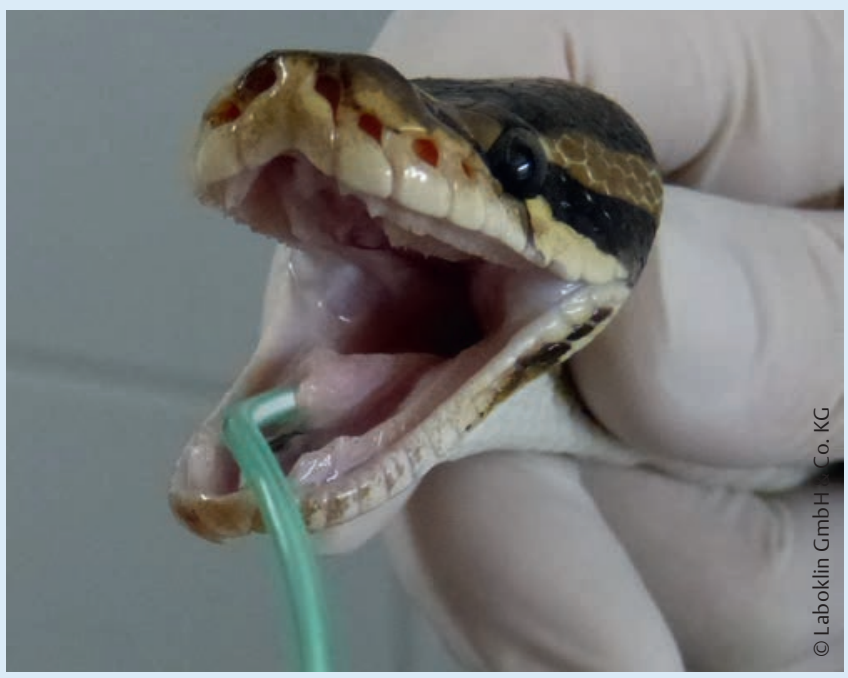

Abb. 1

Trachealspülprobenentnahme bei einer Königspython. Trachealspülproben können zytologisch untersucht werden und dienen der Diagnostik verschiedener Infektionserreger.

\section{Blutuntersuchungen}

Blutuntersuchungen können bei Pneumonien helfen, entzündliche Geschehen zu identifizieren. So kann sich eine Verschiebung in der Anzahl der Granulozyten und Monozyten zeigen. Solche Verschiebungen fallen bei Reptilien jedoch i.d.R. geringer aus als bei Säugetieren.

Bei der Blutchemie können Veränderungen im Gesamtprotein bei Entzündungen vorkommen. Bei schweren Infektionskrankheiten kann die Globulinfraktion bei der Proteinelektrophorese erhöht sein, jedoch sind bislang wenige Normwerte für Reptilien bekannt.

\section{Infektionserreger}

Bakterien und Pilze sind häufig an Pneumonien beteiligt, wobei es sich hierbei meist um fakultativ pathogene Keime handelt. Daneben gibt es einige wichtige Infektionserreger, die als primäre Pathogene bei Lungeninfektionen von Reptilien vorkommen.

\section{Viren}

Ferlaviren (auch als „ophidian Paramyxoviren“ bekannt) werden v.a. bei Schlangen gefunden, können aber auch Echsen und Schildkröten infizieren. Sie können schwere Pneumonien und auch zentralnervöse Störungen verursachen. Sie werden durch direkten Kontakt, aber wahrscheinlich auch durch Aerosole übertragen. Der Nachweis erfolgt v.a. durch eine PCR aus Trachealspülproben sowie aus kombinierten Rachen- und Kloakentupfern bei lebenden Tieren und aus Lungengewebe bei toten Patienten. Ein serologischer Nachweis von Antikörpern gegen Ferlaviren ist möglich. Es wird i.d.R. angenommen, dass einmal infizierte Tiere dauerhaft infiziert bleiben können. 
Reoviren werden v.a. bei Echsen und Schlangen nachgewiesen und lösen zumeist respiratorische Erkrankungen aus. Sie sind aber auch im Zusammenhang mit anderen Erkrankungen, z.B. Glossitis, Papillomen, Enteropathien, Hepatopathien und neurologischen Erscheinungen nachgewiesen worden, jedoch auch bei Tieren ohne klinische Symptome. Sie werden durch eine PCR aus Rachen- und Kloakentupfern nachgewiesen.

Im Jahre 2014 wurde ein neuartiges Nidovirus aus der Familie der Coronaviren bei Pythons nachgewiesen. Das Virus scheint Pneumonien und auch Stomatitiden bei verschiedenen Pythons zu verursachen und kommt relativ häufig vor. Ein Virusnachweis ist mittels PCR aus Trachealspülproben und aus Rachentupfern möglich.

Die Einschlusskörperchenkrankheit (inclusion body disease, IBD), die wahrscheinlich durch Arenaviren verursacht wird, führt zu einer Immunsuppression bei Pythons und Boas. Neben Störungen des ZNS zeigen betroffene Tiere häufig auch Pneumonien. IBD kann auch mit vielen anderen klinischen, wenig spezifischen Symptomen assoziiert sein. Einschlüsse können zytologisch in Blutausstrichen sowie in Biopsien von Leber und ösophagealen Tonsillen nachgewiesen werden. Arenaviren können bei lebenden Tieren aus ösophagealen Tupfern und aus
Vollblut mittels PCR nachgewiesen werden. Der PCR-Nachweis stellt derzeit am lebenden Tier die Untersuchung der Wahl dar. Die Diagnose ist bei Pythons schwieriger als bei Boas.

Bei Pythons in Australien wurde vor einigen Jahren ein neuartiges RNA-Virus, genannt Sunshine-Virus, beschrieben, das respiratorische und neurologische Symptome bei infizierten Schlangen verursacht. Es kann mittels PCR aus kombinierten Rachen-Kloakentupfern nachgewiesen werden.

\section{Bakterien}

Bei den Bakterien gibt es derzeit 2 Gattungen, die als primär pathogene Erreger von Infektionen des unteren Respirationstrakts eingestuft werden: Chlamydien und Mykobakterien. Beide werden i.d.R. mit eitrigen bzw. granulomatösen Entzündungen in verschiedensten Geweben assoziiert. Nachweise können mittels PCR erfolgen. Auch eine histologische Untersuchung mit Anschluss von speziellen Erregerfärbungen (StampFärbung, Ziehl-Neelsen-Färbung) kann Hinweise auf Infektionen mit diesen Erregern liefern. Man sollte weiterhin bedenken, dass einige Spezies ein zoonotisches Potenzial besitzen.

\section{Parasiten}

Bei den Parasiten werden Lungenwürmer (Rhabdias spp.) regelmäßig bei
Schlangen und Echsen gefunden; Eier können mittels Flotation im Kot nachgewiesen werden.

Pentastomiden können v.a. bei Schlangen Lungenerkrankungen verursachen. Sie kommen überwiegend bei wildgefangenen Tieren vor und werden i.d.R. durch bildgebende Verfahren diagnostiziert. Eier können im Kot mittels Flotation nachgewiesen werden. Pentastomiden können Zoonosen auslösen.

Intranukleäre Kokzidien der Schildkröten (tortoise intranuclear coccidia, TINC) können systemische Infektionen bei verschiedenen Schildkrötenspezies hervorrufen und sind als Verursacher von Infektionen des unteren Respirationstrakts bekannt. Die Diagnose erfolgt mittels PCR aus Rachentupfern oder Nasenspülproben.

Online zu finden unter

http://dx.doi.org/10.1055/s-0041-108168
Rachel E. Marschang
Janosch Dietz
Kim O. Heckers
Laboklin $\mathrm{GmbH} \&$ Co. KG
Steubenstr. 4
97688 Bad Kissingen 